\title{
CURRENT REALITIES AND FUTURE AGENDAS FOR CRITICAL CITIZENSHIP EDUCATION
}

\section{INTRODUCTION}

What have been established up to this point? Chapter 1 highlighted three main issues that involve university curricula and critical citizenship education, namely elements of the debate on international curriculum challenges, the debate on national (South African) curriculum challenges as well as challenges linked to curricula engaging "outside" communities. Within the international curriculum arena, four pertinent challenges seem immanent: firstly, an apparent lack of common terminology, language and focus to conduct a proper curriculum discourse; secondly, a lack of curriculum leadership at all levels, including levels of leadership at universities; thirdly, a perceived lack of interest and seriousness in curriculum inquiry; and fourthly, a lack in debate that involve underpinning values that higher education curricula need to promote, particularly in evolving democracies such as South Africa.

At South African universities there appears to be at least three prominent curriculum challenges. This includes a paucity in the debate on the focus of university curricula, whether it be tensions between internationalisation or globalisation, public goods or private goods, or between international, regional or local curriculum relevance; also, demands on university curricula to be increasingly utilitarian in view of pressures exerted by "the world of work" and employability; and challenges related to curricula expected to be more sensitive to communities and constituents "outside" of universities.

On the question of an increased engagement between curricula and its communities, Chapter 1 highlights three salient points: firstly, the evolution of the "knowledge society" and how university curricula have to engage with such emergence; secondly, how university academic staff and their students could engage more productively with service learning, also keeping in mind the benefits of reciprocity; and thirdly, the 
challenge of "critically engaged" curricula as they address institutional autonomy, public accountability and an increasingly differentiated South African higher education system. Chapter 1 has therefore set the scene for exploring the main challenge put forward: how university curricula may promote critical citizenship education in emerging democratic dispensations.

In Chapter 2 we drew extensively on Henry Giroux's scholarly work to use critical pedagogy as a broader lens to focus on the inherent problem of authoritarian curricula and power domination, hinting at promoting emancipatory curricula as historically embedded and socially responsive artefacts. Mediation of learning, as importantly pointed out by Giroux, is to be interrogated by the institutional, the academic and the student voice, as well as "external" voices, as all of these voices represent means of promoting student learning.

What we have established from Giroux's arguments include a number of salient perspectives underpinning elements of critical citizenship education. These include that universities and their curricula should be democratic spaces for open discourse; that student and staff diversity should be celebrated, but at the same time oppose inequality and injustice; that disciplinary boundaries should be permeable in order to address crucial societal challenges; that students and staff should be supported in taking up new epistemological positions and challenges; and that student voices should embed personal narratives into wider social and political contexts so as to transform potential structures of political domination.

By highlighting Giroux's arguments in relation to our own critical citizenship perspective on university curricula, the non-neutral and ideological characteristics of curricula were posited. We agree with Giroux who argues that both curricula and pedagogy are to be regarded as non-neutral devices, and therefore that emancipatory knowledge and practices should be promoted; however, all liberating actions should promote respect and tolerance for the views of others, productive communication and the possibility of being wrong. From Giroux's work we deduced that curricula and pedagogy potentially contain degrees of negative or degenerative historical and societal imprints from the past, especially at the level of the unconscious; therefore, academics and students should be aware of unintentionally promoting the status quo. Giroux's work therefore sets important conditions for critical citizenship education to be enacted in university curricula - particularly in the social and human sciences.

Chapter 3 pointed at three interrelated issues: firstly, how higher education policy changes were effected after 1994 to partially address curriculum transformation. University curricula increasingly considered capability and attribute theories to promote and assess student learning, and links were forged between curriculum 
development and societal change. We therefore explained why critical citizenship education proves important in such processes. Secondly, we have pointed to movements that relate university curricula closer to societal issues and problems and also highlighted that public universities are increasingly expected to strive towards relevant contributions for the public good. Internationally, higher education research and knowledge production agendas include social equity, social cohesion and human understanding. A critical citizenship education perspective in curricula therefore has to include, among other things, a clear definition of the concept of critical citizenship, substantial links to critical thinking and critical pedagogy, some guiding framework for critical citizenship education and forms of identity development that will help students to see themselves as contributing to more just and equal democratic societies. Thirdly and finally we have shown, using some South African examples, that there are different models at work at different universities. Such models may aptly reflect past, present and future institutional contexts and there may not be one best way or model of introducing critical citizenship education into university curricula.

Chapter 4 emphasised the notion that higher education curricula need to be actively engaged to become and remain vibrant within evolving democratic dispensations. We proposed that critical citizenship education may be a worthy perspective to adopt when engaging curricula against the background of what public universities in South Africa should achieve amid its colonial and apartheid backgrounds. In promoting critical citizenship education in curricula, we have suggested that at least four elements of learning, derived from prominent learning theories, are to inform critical citizenship education. These include elements of psychosocial, transformational, socio-political and multicultural theories of learning. All such learning implies curricula that enable students and lecturers to gain new, and sometimes discomforting, personal and societal perspectives. It also implies curricula that promote non-conforming psychological and physical learning spaces that take into account past, current and future political and societal challenges - not only in South Africa, but also globally. What became evident is that engaging curricula via critical citizenship education requires an involved and inclusive approach, amid the fact that the forces striving for power in constructing such curricula are numerous, complex and ever-shifting.

As an example of integrating the theoretical perspectives generated in Chapters 1 to 4, Chapter 5 involved a close look at a critical citizenship education module initiated and implemented at the Department of Visual Arts at Stellenbosch University. The example illustrates the importance of taking the emotional aspects of critical citizenship education for students and academics into account. What we emphasised, however, is that moving beyond emotional reactions towards rational 
actions seems crucial, as the students' reactions in this arts education case showed that they experienced the critical citizenship module as different from other modules. It therefore highlights the importance of strategies such as dialogue, community interactions, reflection and art as mediums for expression. What became evident at the level of practice is that more and longer sessions for student-lecturer-community dialogue may be needed in curricula that promote critical citizenship education so that topics for discussion could be explored in more depth. This implies that curricula have to create safe, but disruptive learning spaces whereby students can discover new realisations about themselves in relation to others and to society. Critical citizenship is therefore not so much about teaching, but about facilitating and promoting experiential, relational and non-hierarchical learning activities with students.

In the rest of this final chapter (Chapter 6) we conclude with three perspectives. Firstly, we highlight the point that engaging university curricula through critical citizenship education needs an inclusive approach - inclusion in the sense of including all university students in intrapersonal and interpersonal transformation as future South African and global citizens; including communities outside of universities in the enactment of university curricula where possible to promote learning and research for the public good; and including lecturers and staff to revisit their possible ingrained ways of planning, promoting and facilitating learning in curricula. Secondly, we propose a conceptual framework for inclusive critical citizenship education that may serve as a guideline to interrogate curricula in higher education, and thirdly we suggest a number of possible agenda points for future research into critical citizenship education.

\section{AN INCLUSIVE APPROACH TO CRITICAL CITIZENSHIP EDUCATION}

Ingrained personal and societal perceptions and attitudes are often not "visible" because they are taken as the norm, and accordingly influence the content and the way in which curricula are structured at the level of the unconscious. Apart from the formal, explicit or documented curriculum, there is therefore always an implicit or "hidden" curriculum by which the perceptions and attitudes of lecturers are invisibly and subtly conveyed. In addition, the "null" curriculum refers to information or issues omitted from the curriculum because it may be regarded as too sensitive or unimportant. Combined capabilities are sometimes needed, because internal capabilities alone do not guarantee success, as such internal capabilities depend on external, suitable conditions. Internal as well as external factors have an influence on learning and what seems evident is that internal psychological and emotional aspects of teaching and learning need to become more prominent in citizenship education and curriculum studies in general. 
The case study in critical citizenship education we presented in Chapter 5 had as an aim to elicit discussions about issues such as power relations, stereotyping or blackness and whiteness. It includes some of the silenced or hidden realities of South African life in discussions and practical projects. It also focuses on personal transformation that would ultimately enhance social transformation through promoting a common set of shared values such as tolerance, diversity, human rights and democracy. The experimental Critical Citizenship module encouraged critical reflection on the injustices of the past to enable imagining a different future. We believe that the conclusions that can be drawn from this case study present realities similar to those faced by many other higher education institutions in South Africa. Although we make no claims towards generalisation, the arts education case paints a significant picture regarding the current position of critical citizenship education and proves to have worthy implications - factual as well as conceptual - for the future of critical citizenship education in South Africa. The sections that follow elaborate on such possible implications derived from this case for an inclusive approach to critical citizenship education in higher education curricula.

On a factual level, the SU case study has shown that critical citizenship education involves an accommodation of a variety of emotional and psychological elements of learning. This case points to the fact that educators should rather start with smaller critical citizenship projects addressing relevant issues in first-year curricula and then increase the effort to more comprehensive projects in later years of study. In contrast to such a "softer" approach, one could, however, also argue that more prominent and major discomfort may be necessary for some students; that through evoking stronger emotional reactions, a possible space for deeper reflection can potentially be created. Curriculum designers and lecturers need to be sensitive to their institutional and student contexts to make accurate judgements in this respect.

Our case study has also shown that pedagogical strategies such as dialogue, community engagement or service learning, reflection and art as mediums for expression seem to be valuable in critical citizenship education. The environment within which such strategies are practised should, however, be a safe space; an equal space where every participant feels comfortable to open up and where each individual can rediscover/reinvent him- or herself in relation to the realities of society. Time is also of the essence, as rushed, more superficial dialogue might not allow participants adequate opportunity to reflect in sufficient depth. To reiterate: Critical citizenship should be something that is not taught, but is experienced by participants in a non-hierarchical manner. 
Facilitating non-hierarchical interaction during critical citizenship education admittedly is a difficult task. For one, the lecturer as facilitator of learning should acknowledge that he or she is a participant in the process - just as his or her students are. Lecturers must therefore be open to lay down their superior "educator" role; indeed becoming facilitators of learning that are personally involved in the process, and they should be prepared to explore deep and sensitive views and issues. Community engagement is an important strategy for critical citizenship education, as it allows learning on an experiential and bodily as well as a cognitive level. However, such engagements can unfortunately also result in hierarchical, asymmetrical interaction. Adjusting the asymmetry may lead to more equal discussions but, as respectful negotiation of difference is one of the key factors critical citizenship education aims to address, any adjustment may deflect from dealing with the really important issues.

When students are confronted with actual and personal interaction within communities not familiar to them, the arts case study has indicated that it becomes a "safe" option to fall back on the notion of "everyone being the same". There is no problem with being the same, but one should be wary that this reaction could mask issues in order to avoid conflict (O'Dowd 2003). Stereotyping one another as similar - or the "other" - may lead to assimilation or denial of differences between individuals, which is not an ideal position for critical citizenship education. In an institutional environment like SU dominated by a white, Western student population and staff, the recognition of other languages and dialects in classrooms could be a way to create a welcoming environment that may enhance inclusivity.

Our arts case also showed that reflective writing can reveal many strong emotional reactions, including resistance as well as hope, and for that reason can be considered as a good strategy to deal with issues related to social transformation. However, reflective writing could be of more value if all participants, including the educators and members from "outside" communities, would write reflections and share it with one another. Participants may then realise that they are on different emotional levels and that might encourage them to find a common space where they could converse and operate as a group.

\section{A POSSIBLE FRAMEWORK FOR INCLUSIVE CRITICAL CITIZENSHIP EDUCATION AND RELATED RESEARCH}

Critical citizenship education is not a concept to be limited to any specific field of interest, as it addresses aspects regarding the negotiation of basic, everyday humanity. The concept of critical citizenship and its engagement with higher education curricula, as we have suggested in this volume, could serve as an example of a project that 
can be adapted, and hence incorporated, into any university department and its curricula. Given the complexity of issues involved with critical citizenship education, many educators might want to avoid it as long as possible. This avoidance of or silence on social issues within the teaching and learning environment is assuredly imprinted onto students and can hence be repeated in society. A re-orientation and development of university staff is therefore crucial for encouraging and incorporating critical citizenship into curricula. Critical citizenship education, when incorporated into various departments or faculties, could encourage further research into different strategies, approaches and applications to collaboratively work towards personal and social transformation.

Only through actual practical implementation of critical citizenship education can one learn from experience. Each educational setting has its own unique characteristics, which implies that one has to implement and experience a course or a module in its specific setting or context before any limiting or promotional aspects can be identified. A point of concern is that the students involved will, in most instances, be considered as "guinea pigs" to enable curriculum engagement. One can therefore say that engaging curricula involves a constant process of generating ideas, trying them out and improving while students and lecturers are experimenting and learning simultaneously. This stance differs from often held perceptions that curricula are designed by some kind of authority, after which they are implemented and students learn best from it. To effectively make progress with critical citizenship education, its practitioners and advocates need to be open and accepting it to involving constant curriculum change and evolution.

To educate for critical citizenship, lecturers need to have subject knowledge (e.g. in art and design, chemistry, theology, sociology), experience in working with communities and an interest in and awareness of critical citizenship education. This is not a common combination of skills, but skills that need to be learned. In the Department of Visual Arts at SU, for instance, accruing such skills has led to introducing a master's degree in Art Education with a strong focus on critical citizenship to develop and enhance such capabilities of future art and design (school) teachers and (university) lecturers. Similar programmes can potentially also be developed in other fields of study.

In relation to having an adequate background - and given the segregated history of South Africa - the cultural affiliation of educators and researchers in the field of critical citizenship have to play a role in the process of critical citizenship education. Different results can potentially be obtained if, for example, a researcher or lecturer is black, coloured or white and speaks Xhosa, English or Afrikaans or any combination of such languages. For that reason, it is suggested that similar 
research be done by representatives of a range of cultural backgrounds so that critical citizenship education in curricula can be investigated and promoted from various vantage points.

Conceptually, social transformation cannot be separated from the individual citizen. The term "social transformation" connotes change in policies as well as personal change. Choosing the word "social" instead of "personal" already distances transformation from the individual. This makes it easier to perceive transformation as something "out there" and not within oneself. The Critical Citizenship module relevant to the case study we discussed in Chapter 5 was aimed at addressing issues on a more personal level and not assuming that general conversation about social transformation would have an effect on the personal. In general, the students' reactions showed that they experienced the module as different from other modules, not only because it involved action research and community engagement, but also because they realised it encompassed personal involvement and potential personal change. The students who responded that they were specifically targeted to adjust their perceptions and attitudes and that the broader community should also be targeted were correct. Community engagement should not only be included because it is to the benefit of students' learning only, but because the learning is reciprocal. Critical citizenship education in the form of addressing issues such as tolerance, diversity, human rights, democracy and social justice should therefore be to the understanding and benefit of all participants.

Developing an inclusive curriculum that includes communities outside the university might seem undoable in all university curricula, but the consequences of not including communities where possible, especially in an unstable and evolving democratic society such as in South Africa, could be detrimental. Higher education curricula could contribute to a more stable society by including critical citizenship education on a broader scale with a broader societal reach. Inevitably, many South African universities have contributed hugely to society over the years, but often in very specific ways so that the distance and knowledge gaps between universities and society remained. The aim of introducing community engagement in university curricula is to narrow the gap between universities and their communities. However, communities may often remain in a position of need and a need of agency. Teaching a community member a skill such as art could be valuable, but developing critical thinking skills could be even more valuable. The central concern should be how critical thinking skills can be developed through another medium, such as art and design, literature, chemistry or whatever field critical citizenship education is being practised in. 
The current values of SU express a readiness to serve the interest of and being responsive to the needs of communities. It also stresses responsibility towards communities through serious consideration of the implications of actions. The implications of community engagement in the form of service or charitable actions could be that the hierarchy of the knowledgeable and the needy and the perpetuation of power relations remain. If critical citizenship could be included in all curricula involved with community engagement projects at higher education institutions, there could be greater range of problematic issues within such interactions, but it could also contribute to a society that is better informed to make responsible decisions. An inclusive critical citizenship education curriculum for students, lecturers and community members on a broader scale is therefore suggested.

In the same way that good political leadership can potentially influence society positively, a lecturer who develops an inclusive critical citizenship curriculum or incorporates critical citizenship education into a curriculum can potentially influence students and community members as an educator. However, there is a better chance of an educational institution educating people to think critically and responsibly than, for instance, a political party. In the latter case, the aim may be only to convince the members of a community to vote for their party. That does not mean that an educational institution cannot use its position of assumed power to influence people to vote for a certain party. Hidden power relations could infiltrate even with the best intentions one may have for inclusive critical citizenship education, and therefore one should be cognisant of this possibility under all circumstances.

Obviously, educational transformation cannot be separated from political and social transformation. An educational institution's responsibility regarding social transformation is therefore extended by not only incorporating community interactions into its curricula, but also by including critical citizenship education in community engagement and educating society on a larger scale. The focus of educational institutions is therefore not only on educating intellectuals that lead society or indirectly influence society, but also to play a role in educating society directly. The implications of inclusive critical citizenship education therefore require major institutional, departmental and personal shifts. Without deep personal reflection and the practice of tolerance, diversity, human rights and social justice, inclusive critical citizenship education could become just another mask to show that educational institutions are doing their utmost to break down both an ivory tower mentality and the knowledge divide. A top-down transformation project can for instance be implemented in an institution that enforces changes in the content of courses but the lecturer and environment might not change. This could result in limited progress 
in facilitating critical citizenship education. Figure 6.1 portrays a potentially useful conceptual framework of inclusive critical citizenship education that may be applied in various contexts - especially in South Africa with its particular history and evolving democratic status.

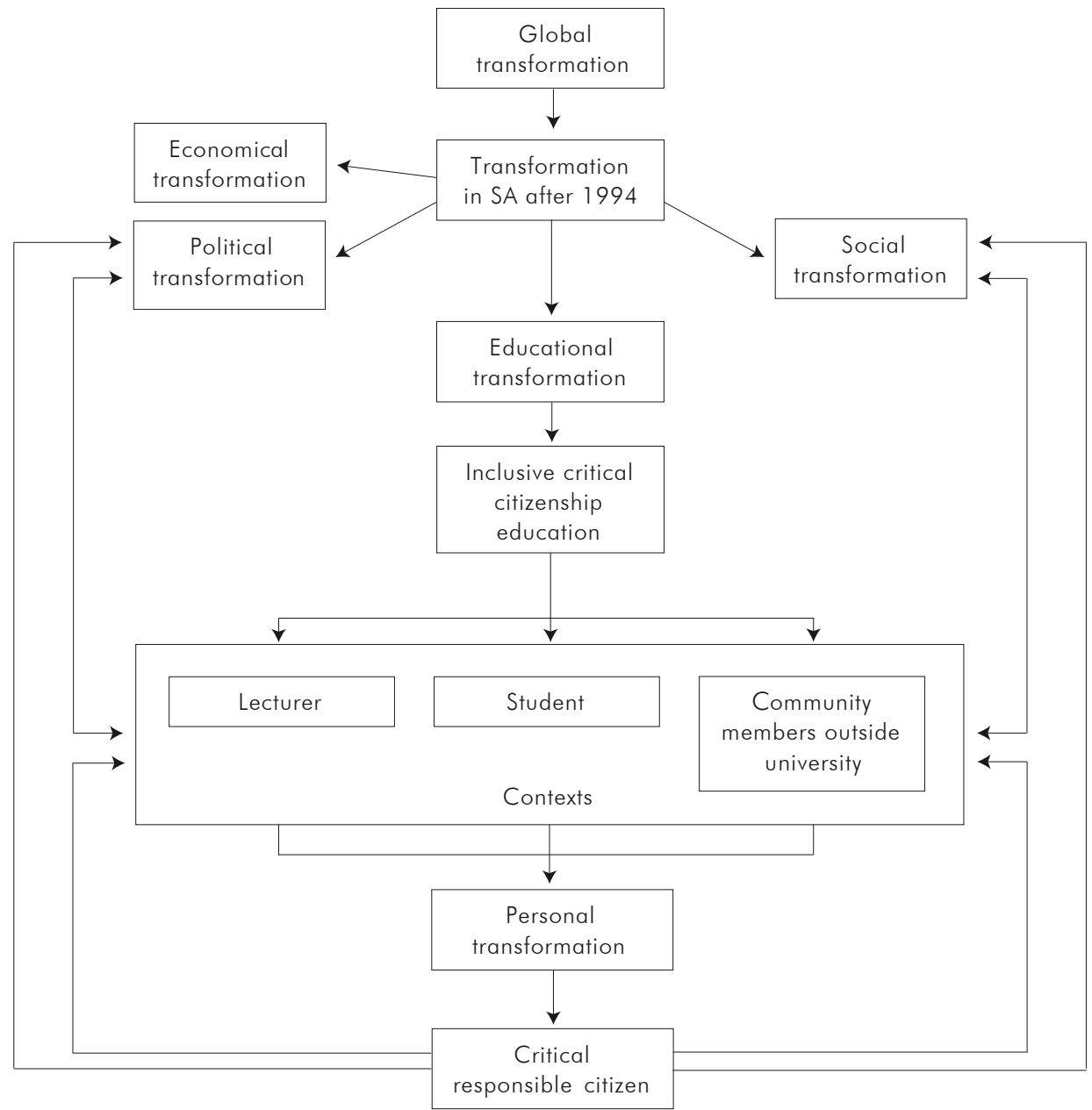

FIGURE 6.1 A framework for inclusive critical citizenship education

Against this background we suggest, as depicted in Figure 6.1, that to enable social transformation on a bigger scale, critical citizenship has to be promoted and facilitated to include university academics, students and "outside" civic communities. The context in which critical citizenship education takes place could be vital and 
that also has an influence on personal transformation that should ideally result in a critically responsible citizen. What happens outside the classroom could have a strong influence on students and lecturers. Critical citizenship education should therefore also be facilitated outside the classroom on campus and in social environments. This may result in personal transformation on a scale beyond the individual institution that could have a broader effect on social and political transformation in general. Currently, the participation rate in university education in South Africa is approximately $18 \%$. This is low compared to those not participating in university studies and potentially exposed to critical citizenship education. Facilitating inclusive critical citizenship education should therefore take place inside of classrooms, outside classrooms as well as in communities outside the university. Community engagement and service learning could be an ideal opportunity to facilitate critical citizenship education to all participating - students, lecturers and community members.

A transformative framework such as the one portrayed in Figure 6.1 may not address all issues regarding curricula that embrace critical citizenship education. What it does, however, is draw together some of the points we have alluded to earlier, namely to:

- present new possibilities for higher education institutions, through their curricula, to promote transformation in a global sense, but particularly in developing democracies such as South Africa;

- help establish a new set of values that are sensitive to citizenship and citizenship education through various platforms of learning;

- establish curricula as democratic learning spaces that potentially oppose authoritarianism and domination, that support permeating disciplinary boundaries where possible and look into issues of increased relevance to South African society;

- encourage links between transformational policy initiatives and personal and societal change through a variety of models by introducing critical citizenship education into curricula wherever possible;

- progressively use proven and relevant elements of applicable learning theories to effect transformation of learning and promote the involvement of every student and lecturer in citizenship education; and

- undertake explorative work in higher education curricula that promotes reciprocal learning between students, lecturers and civic communities.

Hardt (2004:61) argues that "thinking of politics now as a project of social transformation on a large scale, I'm not at all convinced that political activity can 
come from the university". We therefore argue that universities, through their curricula, should become involved in broader society to influence social transformation, otherwise society as a whole will not change. It is often in the interest of politicians to keep the majority of society uninformed so as to be able to manipulate people. University education, because of relatively small numbers, only affects a small but crucial percentage of the population. However, a broadening of the university's role can only take place if the internal social transformation of the university itself has already taken place and includes critical citizenship values such as tolerance, diversity, human rights, democracy and social justice.

At the project level, as indicated by the arts case study, the "Design as healing" project confirmed that students enjoy working with personal issues in their practical projects. It is interesting that, even though the students in this case study preferred to work with personal issues in their own projects, some showed resistance when they realised that personal transformation was involved. In this regard, art and design processes, whereby students express themselves in ways other than in writing or verbally, could be explored further as a means of interrogating personal issues indirectly. All art forms have the potential to bring out the emotional and imaginative and a different understanding of life, as aesthetics comprises the nature of experience, perceptions, feelings and emotions and relates to issues of subjectivity and identity (Kul-Want 2007). Aesthetic processes and exploration work on a subconscious level and therefore have the potential to change norms and values, which is essential and valuable in critical citizenship education.

\section{SOME POINTS FOR A RESEARCH AGENDA IN CRITICAL CITIZENSHIP EDUCATION}

Our research for this volume has opened up a number of interesting possibilities for further research into critical citizenship education in university curricula. We highlight and discuss a number of such possibilities which are, inevitably, not an exhaustive list.

Values such as tolerance and diversity inevitably have emotional dimensions. Lifting discussion and learning from the emotional to the cognitive could enable students to realise that terms such as tolerance and diversity - on a rational level - are vital. Getting past the emotions that could cause barriers to enable thinking rationally and critically should be priorities in critical citizenship education. Our experimental investigation into students' emotional reactions to the Critical Citizenship module, as discussed in Chapter 5, resulted in themes such as guilt and shame, resistance to learning, intolerance, assimilation and asymmetrical learning environments, but also revealed what provides many students with hope to continue and persevere. Further 
research that focuses on how each of these themes can be negotiated in a practical sense could present valuable information towards constructing engaged curricula at a practical level in future.

Also, it has been suggested that humans, almost above all else, dread changes that deeply modify, reshape and remake the ego-self (see Reanney 1991). Human evolution has ensured the human instinct to protect oneself from personal change because our ego-self becomes unstable. Learning non-personal information is therefore easier, because it does not immediately affect the psychological ego-self. Critical citizenship education therefore falls in the area of personal transformation and is therefore far more difficult to facilitate in university curricula, which, on average, deal mostly with cognitive learning. Further research in critical citizenship education that naturally involves emotional and personal transformative learning and teaching could therefore be valuable, particularly in cooperation with experts on cognitive psychology and neuroscience.

Critical citizenship education often explores emotional issues that are hidden in the subconscious mind. Freud accentuated our failure to recognise deep conflicts of the psyche because of unresolved emotions (in Stevenson 1996). We constantly struggle to make sense of complex experiences and cannot step outside our reality or context. Freud suggested that it is not essential to resolve emotions or feelings, but important to bring it to the conscious (in Stevenson 1996). Strategies used to do this, such as the processes of art and design, dialogue, community engagement and reflective writing, are however quite complex. As little in-depth research has been done on strategies for moral or critical citizenship education, further research could be valuable in relation to the use of such strategies as a medium for changing perceptions and attitudes.

Dualisms are already so ingrained in society that our minds almost automatically think in opposites. In the definition of critical citizenship, the term "diversity" refers to seeing the diverse aspects on a continuum between two opposite poles. A person, for instance, is not either tolerant or intolerant. A person can be very tolerant towards certain aspects, but less tolerant to other aspects of a fellow student or learner. To acquire tolerance is to learn all the subtle nuances between the extremes of being tolerant and not tolerant. Dualistic mind sets often surfaced in the data from our Critical Citizenship module case, particularly in relation to various religious belief systems. Ancestral and Christian beliefs often came to the fore in the arts case, and how to facilitate critical citizenship education against such backgrounds and value systems may be an issue that would make for interesting further investigation, particularly as such belief systems may enhance or inhibit transformational learning. 
In casting one's vision further afield, it should be realised that critical citizenship education should aim to contextualise learning locally as well as globally. We feel strongly that there lies value in students first developing a deep connection with their immediate and local frameworks and accompanying emotional and psychological states before encouraging them to see the ever bigger and global spheres. Connecting students and classes in various countries through technology may be useful, but because of the segregated past in South Africa, many university students and staff do not know their own neighbouring suburbs. Connecting locally is therefore as important as connecting globally. Western cultures in South Africa were and still, to some extent, feel more connected to countries in Europe than Africa. Connecting design students from other African countries to those in South Africa, for instance, could be as valuable, if not more valuable as connecting with design students at universities in Europe or elsewhere. Research into issues regarding the avoidance of local social responsibilities and a preference for global citizenship and its implications for critical citizenship education may provide answers to some of these dualistic challenges.

Critical citizenship as a curriculum issue relates to critical thinking that may lead to individual transformation and the development of responsible and accommodating individuals in multicultural societies. Like most existing social and philosophical theories, critical citizenship or critical citizenship curricula concepts originated in North America and Europe. In South Africa, it has become a crucial issue following the end of the apartheid regime in 1994, especially with the obliteration of the notion of white supremacy as a national policy and the entrenchment of a multicultural matrix in which the notion of skin colour or race accentuation no longer exists. No doubt, there are similar issues of settlers and original owner of land issues, coupled with ethnic rivalry, corruption, a culture of impunity and religious intolerance leading to unending wars, bitterness and civil strife in Africa. Such debilitations often result in a vicious circle of underdevelopment and other untoward situations in Africa. Solutions to the problem based on the examination of the causes and consequences of colonial and post-colonial periods seem not to have yielded results.

What are therefore needed are alternative solutions to these problems through the possibilities of educational curricula that can be used as devices to shape development if based on the promotion of a common set of values. Critical citizenship education, for example, can teach values such as tolerance at all levels within the family, religious organisations, at personal and interpersonal levels and across race, age and gender, among others; including respect for diversity and human rights beyond its use as a slogan for a system of government, but as intrinsic and internalised by the individual in all its ramifications (Johnson \& Morris 2010:77, 78). This form 
of transformation is not restricted to apparent or physical transformation, but also includes cognitive transcendence. It involves economic and social transformation - aspects that often receive less attention in educational curricula. There may be many more issues to explore, but for further future research into critical citizenship education and deliberation we suggest themes such as the following:

- Re-thinking higher and critical citizenship education in Africa

- Curriculum planning, development and implementation for critical citizenship

- Indigenous knowledge systems and critical citizenship

- Disciplines with permeable boundaries for critical citizenship education

- Technological advancement and critical citizenship

- Religion and critical citizenship.

In writing this volume, we have aimed to provide some background as well as theoretical and empirical substance towards exploring higher education curricula from a critical citizenship education perspective. By providing a sound theoretical base as well as practical examples of the application of critical citizenship education in a specific higher education context in South Africa, we hope that it may contribute to assist others scholars and practitioners to explore in and learn from their own unique curriculum environments. We also hope that this volume may serve as impetus for further research in the field and thereby contribute to further developing a socially just and democratic South Africa and world. 